\title{
The Performance of Glycated Hemoglobin vs. Oral Glucose Tolerance Test in the Diagnosis of Glycemic Disorders among Women with Polycystic Ovary Syndrome in Southern Iraq
}

\author{
Mahmood Thamer Altemimi ${ }^{1,2 *}$, Alaa Khattar Musa ${ }^{3}$, Abbas Ali Mansour ${ }^{1}$ \\ ${ }^{1}$ Faiha Specialized Diabetes, Endocrine and Metabolism Center (FDEMC), University of Basrah, Basrah, Iraq \\ ${ }^{2}$ Basrah Health Directorate, Basrah, Iraq \\ ${ }^{3}$ College of Medicine, University of Basrah, Basrah, Iraq \\ *Corresponding author. E-mail: mahmoodaltimimi83@gmail.com
}

Received date: Oct 28, 2020; Revised date: Mar 28, 2021; Accepted date: Apr 5, 2021

\section{Abstract}

$\mathrm{B}$ ACKGROUND: Obese women with polycystic ovary syndrome (PCOS) are at high risk for developing type 2 diabetes mellitus (T2DM). A baseline oral glucose tolerance test (2-h OGTT) is important to screen for dysglycemia in PCOS particularly those high risk women. Due to its advantages by fasting is not required and less day-to-day variability, glycated hemoglobin (HbAlc) might be a convenient screening tool. This study aimed to evaluate the performance of HbAlc vs. 2-h OGTT in the diagnosis of glycemic disorders in PCOS and to evaluate the correlation between glycemic disorders, insulin resistance (IR), and anthropometric measures.

METHODS: One hundred and twenty nine women diagnosed with PCOS according to the Rotterdam 2003 criteria in Basrah were included in the study. All subjects were examined for weight, body mass index (BMI) and waist circumference (WC). Then they were tested for fasting glucose, 2-h OGTT, HbA1c, and fasting insulin to assess IR.
RESULTS: The result of 2-h OGTT test showed that there were 21 subjects $(16.1 \%)$ showed to have IGT. The result of HbA1c test showed that 25 subjects (19.4\%) were diagonised with prediabetes. Meanwhile FPG test result showed that 34 subjects $(26.4 \%)$ were having IFG. The HbAlc examination showed an underdetected the diagnosis of T2DM $(0.8 \%)$ and an overdeteced diagnosis of prediabetes $(19.4 \%)(p=0.021)$ and at $\mathrm{HbAlc} 5.55 \%(37.2 \mathrm{mmol} / \mathrm{mol})$, the specificity was (74.3\%) and sensitivity (56.5\%) to discriminate normal from abnormal glucose status. Ninety nine women (76.7\%) were either overweight or obese and most of them had IR (76.8\%).

CONCLUSION: Screening of glycemic disorders is crucial for PCOS by using 2-h OGTT regardless of risk factor and $\mathrm{HbAlc}$ seems to be an unsatisfactory screening tool to predict glycemic disorders in women with PCOS.

KEYWORDS: PCOS, glycemic disorders, OGTT, HbA1c, insulin resistance, and prediabetes

Indones Biomed J. 2021; 13(2): 178-85

\section{Introduction}

Polycystic ovary syndrome (PCOS) is a common metabolic and endocrine disorder of women at reproductive age.(1) Women with PCOS, especially obese ones are at an increased risk for developing metabolic syndrome with dysglycemia, around $31-35 \%$ for impaired glucose tolerance (IGT) and $7.5-10 \%$ for type 2 diabetes mellitus (T2DM). The average period for progression from normal glycemic status to IGT, and then to T2DM, may be approximately $5-15 \%$ during 3 years.(2) Insulin resistance (IR), and the development of compensatory hyperinsulinemia, are frequent findings in PCOS.(3) However, the mechanism for the excess insulin resistance and hyperinsulinemia in PCOS remains not understood.

Many evidence suggested a baseline oral glucose tolerance test (2-h OGTT) every 1 to 2 years is an important 
especially among PCOS who are having a family history of T2DM or high body mass index (BMI) and yearly in women with IGT.(2) This protocol seems to be acceptable due to the difficulty to perform 2-h OGTT in a prevalent condition such as PCOS, it is also a time-consuming test.

American Diabetes Association (ADA) suggested that glycated hemoglobin (HbAlc) and fasting glucose (FPG) are as appropriate as 75 gram 2-h OGTT to diagnose T2DM or prediabetes in general populations. However, according to previous systematic review, FPG has been classified as an insufficient screening tool to predict dysglycemia in PCOS.(4) Because of its advantages over FPG and 2-h OGTT, in term of not needing fasting before the test and less daily variability during periods of stress or illness, $\mathrm{HbAlc}$ might be considered a satisfactory screening tool. HbAlc also provides a better estimate for health care providers regarding chronic glycemic control.

Because of those reasons, this study aimed to evaluate the performance of HbA1c vs. 2-h OGTT in the diagnosis of glycemic disorders in women with PCOS and to evaluate the correlation between glycemic disorders, insulin resistance, and anthropometric measures of women with PCOS.

\section{Methods}

\section{Study Design and Subjects}

A cross sectional study was carried out in Faiha Specialized Diabetes, Endocrine, and Metabolism Center (FDEMC), University of Basrah, Iraq, during September 2019 to September 2020. An ethical approval was obtained from the Research Ethics Committee at College of Medicine, University of Basrah. We alos obtained informed consents from each patient.

The subjects were premenopausal women who were diagnosed with PCOS according to Rotterdam 2003 criteria $(5,6)$ and they were not previously diagnosed with T2DM. Women with the following conditions were excluded from the study: pregnant women, having hemoglobinopathies like sickle cell disease and thalassemia, having iron deficiency anemia (IDA), having previous history of type 1 diabetes mellitus (T1DM) or T2DM, having over-thypothyroidism and hyper-prolactinemia, and on metformin or pioglitazone therapy for either fertility or as insulin sensitizers or were using glucocorticoids in last 3 months.

\section{Clinical Evaluation}

A careful gynecological history was taken from all women including age of menarche, menses cycle length and regularity, marital status, parity, fertility and the use of medication. The standard anthropometric measurements including weight, height and waist circumference (WC) in centimeters were examined. Height was measured by using seca ${ }^{\circledR} 217$ mobile stadiometer (Seca, Chino, CA, USA) while the subject was standing upright. Subjects' weight was measured by using seca ${ }^{\circledR 763}$ electronic weight station (Seca). WC was measured at midway point between the lower costal margin and the iliac crest while the subject was standing. Central obesity was documented when WC is $\geq 99$ $\mathrm{cm}$.(7) The BMI was calculated as the weight measured by kilograms divided by the height in meters after squaring it. Normal BMI was defined as BMI $<25 \mathrm{~kg} / \mathrm{m}^{2}$ and overweight/ obesity as BMI $\geq 25 \mathrm{~kg} / \mathrm{m}^{2}$. Hypertension was defined as a known hypertensive subject treated by a certain medicine, or if the systolic blood pressure (SBP) $\geq 135 \mathrm{mmHg}$ and or diastolic blood pressure (DBP) of $\geq 85 \mathrm{mmHg}$. (8)

Hyperandrogenism was documented by the presence of elevated serum androgen levels or the presence of androgenetic alopecia or hirsutism which was defined by a modified Ferriman-Gallwey (m.FG) hirsutism score $\geq 8$.(9) Hair growth was assessed in nine areas of the body and face of each woman on a scale of 0-4: chin, upper lip, chest, upper and lower back, upper and lower abdomen, arms and thighs. The sum of all these scores represents the hirsutism score (total m.FG score) which was examined by a single well trained investigator to avoid the inter-subject variability. Biochemical hyperandrogenism was documented when a serum total testosterone (TT) was $>46 \mathrm{ng} / \mathrm{dL}(1.59 \mathrm{nmol} / \mathrm{L})$ or calculated free testosterone (FT) level was $>0.56 \mathrm{ng} / \mathrm{dL}$ (0.019 nmol/L).(10)

Polycystic ovarian morphology (PCOM) was achieved with either one or both of the following: ovarian volume of $>10.0 \mathrm{~cm}^{3}$, assessed by the use a three-dimensional ellipsoid formula ( $0.5 \mathrm{x}$ length $\mathrm{x}$ width $\mathrm{x}$ thickness; and/or the existence of 12 or more follicles measuring 2 to $9 \mathrm{~mm}$ in diameter in the ovarian cortex, estimated from the mean of both the longitudinal and anteroposterior cross sections of the ovaries. Presence of either one of these features in only one ovary was satisfactory for defining the presence of PCOM.(11) Cushing syndrome was excluded by a value of basal cortisol within normal reference range.

\section{Basal Hormonal Measurement}

An eight milliliters of venous blood sample was collected from each woman at early morning 8:00-10:00 am after an overnight fasting for 8-10 hours in the early follicular-phase of the spontaneous menstrual cycle (day 3-5) or at any day for amenorrhoeic women. The hormonal assessment 
was done to confirm biochemical hyperandrogenism of PCOS after excluding other diagnoses like hypothyroidism, hyperprolactinemia, Cushing syndrome, and non-classical congenital adrenal hyperplasia (N-CAH). A follicular-phase basal 17 $\alpha$-Hydroxyprogesterone (17-OHP) $>495 \mathrm{ng} / \mathrm{dL}$ (15 nmol/L) and/or adrenocorticotropic hormone (ACTH) stimulated 17-OHP $>1000 \mathrm{ng} / \mathrm{dL}(30 \mathrm{nmol} / \mathrm{L})$ in women, was diagnostic for nonclassic congenital adrenal hyperplasia (N-CAH) to be excluded.(12) The TT and sex hormonebinding globulin (SHBG) were measured concurrently on the same day. Calculated FT were measured from TT, SHBG and albumin.(13)

\section{Metabolic Profiling}

FPG was measured to all women by Cobas 311 (Roche Diagnostics, Mannheim, Germany). Homeostasis-Model Assessment of IR (HOMA-IR) formula was used to assess IR as (Fasting serum insulin $(\mu \mathrm{U} / \mathrm{mL}) \times$ FPG $(\mathrm{mmol} 1-1) / 22.5)$ and a value of 2.11 or more was considered as a diagnostic for IR.(14) A $75 \mathrm{~g}$ anhydrous glucose was dissolved in 250 $\mathrm{mL}$ water and was having by each woman under supervision then a plasma glucose was measured after 120 minutes. On the same day of measuring 2-h OGTT, HbAlc was done to all subjects. According to ADA criteria, glycemic state was defined as follows: Prediabetes: $F P G=100-125 \mathrm{mg} / \mathrm{dL}$ (5.6-6.9 mmol/L) and/or 2-h OGTT=140-199 mg/dL (7.8$11.0 \mathrm{mmol} / \mathrm{L})$ and $/$ or $\mathrm{HbAl}=5.7-6.4 \%(39-47 \mathrm{mmol} / \mathrm{mol})$; T2DM: FPG $\geq 126 \mathrm{mg} / \mathrm{dL}(7 \mathrm{mmol} / \mathrm{L})$ and/or 2 -h OGTT $\geq 200 \mathrm{mg} / \mathrm{dL}(11.1 \mathrm{mmol} / \mathrm{L})$ and/or HbAlc $\geq 6.5 \%$ (48 $\mathrm{mmol} / \mathrm{mol}) .(4)$

\section{Assay Technique}

Electrochemiluminescence technology for immunoassay analysis by Elecsys 2010 ®Assays Cobas E-411 Analyzer (Roche Diagnostics) was used for hormonal measurement. Specified intra-assay precision with reasonable coefficient of variance $(\mathrm{CV})$ for each hormone was assessed as the following: TT: $15-46 \mathrm{ng} / \mathrm{dL}(0.27-1.59$ nmol/L) $(\leq 6 \% \mathrm{CV})$; SHBG: $18-86 \mathrm{nmol} / \mathrm{L}(<4 \% \mathrm{CV})$; dehydroepiandrostenedione sulfate (DHEA-S): 145-395 $\mu \mathrm{g} / \mathrm{dL}(<5 \% \mathrm{CV})$ for women aged $18-19,65-380 \mu \mathrm{g} / \mathrm{dL}$ for women aged 20-29, 45-270 $\mu \mathrm{g} / \mathrm{dL}$ for women aged 30-40; thyrotropin (TSH): $0.27-4.2 \mu \mathrm{IU} / \mathrm{mL}(<5 \% \mathrm{CV})$; prolactin: 4-30 ng/mL ( $\leq 5 \% \mathrm{CV})$; cortisol 5-25 $\mu \mathrm{g} / \mathrm{dL}$ (137.93-689.65 $\mathrm{nmol} / \mathrm{L})(<6 \% \mathrm{CV})$; ACTH: $10-60 \mathrm{pg} / \mathrm{mL}(2.2-13.2 \mathrm{pmol} / \mathrm{L})$ $(<5 \% \mathrm{CV})$; follicle-stimulating hormone (FSH): 2-12 mIU/ $\mathrm{mL}(\leq 4 \% \mathrm{CV})$; luteinizing hormone (LH): $2-18 \mathrm{mIU} /$ $\mathrm{mL}(\leq 5 \% \mathrm{CV})$; insulin: 2.6-24.9 $\mu \mathrm{U} / \mathrm{mL}(<4 \% \mathrm{CV})$; and estradiol: $27-136 \mathrm{pg} / \mathrm{mL}(<4 \% \mathrm{CV})$. Enzyme linked immunosorbent assay (ELISA) (Bio-Tech $\mathrm{GmbH}$, Nordost, Germany) was used to measure 17-OHP $\leq 495 \mathrm{ng} / \mathrm{dL}$ (15 nmol/L) $(<10 \%$ CV). Bio-Rad Variant II Turbo HbA1c Kit 2.0 Quick Guide 270-2455EX (Bio-Rad, Hercules, CA, USA) was used to measure $\mathrm{HbA} 1 \mathrm{c}$.

\section{Statistical Analysis}

Data analysis was performed using Statistical Package for the Social Sciences Version 23.0 (SPSS Inc., Chicago, IL, USA). Statistical significance was set at $p<0.05$. Analysis of variance (ANOVA) and independent student t-test were used to study the continuous variables while Chi square test was used for non-parametric variables. Receiver Operating Characteristic (ROC) curve for $\mathrm{HbAlc}$ at $95 \%$ confidence interval (CI) was used to predict the specificity and sensitivity of value that discriminate normal from abnormal glucose state.

\section{Results}

Total of 129 subjects with a mean age $26.3 \pm 6.85$ years old were diagnosed with PCOS. The average of the subjects were considered as overweight or obese $(31.37 \pm 7.69 \mathrm{~kg} /$ $\mathrm{m}^{2}$ ). The baseline characteristics of subjects diagnosed with PCOS were summarized in Table 1.

The result of 2-h OGTT test showed that there were 21 subjects $(16.1 \%)$ showed to have IGT. The result of HbAlc test showed that 25 subjects (19.4\%) were diagonised with prediabetes. Meanwhile FPG test result showed that 34 subjects $(26.4 \%)$ were having IFG (Table 2). Fourteen subjects $(66.7 \%)$ of truly IGT were misdiagnosed as normal glycemic state by HbA1c test and 17 subjects (16\%) were misinterpreted to be prediabetes by HbA1c test despite they had normal glycemic state by 2-h OGTT. The comparison between 2-h OGTT and HbAlc tests showed a significance difference $(p=0.021)$, so does the comparison between 2 -h OGTT and FPG tests $(p<0.001)$.

According to their BMI, 99 subjects (76.7\%) were classified as overweight/obese PCOS, while the 30 subjects (23.2\%) were classified as lean PCOS. Overweight/obese subjects were significantly older and having a higher WC with higher SBP than lean women $(p=0.001, p<0.001$, $p=0.034$, respectively) (Table 3 ). Fasting insulin and FT were not statistically different between the two groups ( $p=0.394, p=0.333$, respectively) However, a high TT, low SHBG and high DHEAS were significantly found among overweight/obese PCOS subjects compared to the lean ones ( $p=0.041, p=0.007, p=0.034$, respectively). 
Table 1. Baseline characteristics of subjects diagnosed with PCOS (n=129).

\begin{tabular}{lccc}
\hline \multicolumn{1}{c}{ Variables } & Mean \pm SD & Minimum & Maximum \\
\hline Age (years) & $26.30 \pm 6.85$ & 15 & 43 \\
BMI $\left(\mathrm{kg} / \mathrm{m}^{2}\right)$ & $31.37 \pm 7.69$ & 16.02 & 51.55 \\
WC $(\mathrm{cm})$ & $96.10 \pm 15.5$ & 72 & 144 \\
SBP $(\mathrm{mmHg})$ & $123.57 \pm 13.21$ & 94 & 161 \\
DBP (mmHg) & $75.19 \pm 10.78$ & 41 & 96 \\
2-h OGTT (mg/dL) & $116.97 \pm 33.93$ & 47 & 296 \\
FPG (mg/dL) & $94.10 \pm 10.87$ & 67 & 137 \\
HbA1c (\%) & $5.25 \pm 0.50$ & 3.9 & 6.5 \\
Fasting insulin $(\mu \mathrm{U} / \mathrm{mL})$ & $18.50 \pm 21.82$ & 3.98 & 213 \\
HOMA-IR (\%) & $4.36 \pm 5.63$ & 0.78 & 58.37 \\
TT (ng/dL) & $35.80 \pm 22.30$ & 2.5 & 113 \\
FT (ng/dL) & $0.71 \pm 0.55$ & 0.03 & 3.34 \\
SHBG (nmol/L) & $40.26 \pm 33.79$ & 4.3 & 191 \\
DHEA-S $(\mu \mathrm{g} / \mathrm{dL})$ & $234.40 \pm 122.90$ & 43.25 & 595.4 \\
FSH (mIU/mL) & $5.20 \pm 2.16$ & 0.9 & 16.47 \\
LH (mIU/mL) & $7.90 \pm 5.57$ & 0.1 & 37 \\
17-OHP (ng/dL) & $221.90 \pm 97.83$ & 50 & 460 \\
m.FG score & $17.0 \pm 6.0$ & 0 & 32 \\
Androgenic alopecia & $2.0 \pm 1.0$ & 0 & 5 \\
\hline
\end{tabular}

The pattern of glycemic disorders between overweight/ obese and lean PCOS subjects was presented in Table 4 . The mean FPG in both groups were comparable $(95 \pm 11.22$ $\mathrm{mg} / \mathrm{dL} v s .91 \pm 9.11 \mathrm{mg} / \mathrm{dL}$ ) for overweight/obese and lean PCOS, respectively, with a $p=0.081$. The mean HbA1c of overweight/obese PCOS subjects were $5.26 \pm 0.51 \%$ which was close to the mean $\mathrm{HbA} 1 \mathrm{c}$ of the lean women $5.07 \pm 0.43 \%$ ( $p=0.92$ ), hence not significantly different. After 2-h OGTT, overweight/obese subjects were having a statistically significant higher mean plasma glucose $119.32 \pm 33.46 \mathrm{mg} /$
$\mathrm{dL}$ than the lean women $103.96 \pm 32.62 \mathrm{mg} / \mathrm{dL}(p=0.033)$. IR was seen in 90 subjects (69.8\%) with PCOS. With $76.8 \%$ in overweight/obese PCOS subjects and $46.7 \%$ in lean PCOS subjects $(p=0.002)$.

ROC curve for HbAlc was used to predict the specificity and sensitivity of value that discriminate subjects of normal glucose state from the abnormal one. A cut-off value of $5.55 \%(37.2 \mathrm{mmol} / \mathrm{mol})$ for $\mathrm{HbAlc}$ has the most acceptable specificity (74.3\%) but low sensitivity (56.5\%) to discriminate subjects diagnosed with PCOS who have

Table 2. Comparative study among HbA1c, FPG and 2-h OGTT to diagnose glycemic disorders in subjects with PCOS.

\begin{tabular}{|c|c|c|c|c|c|c|}
\hline & \multirow{2}{*}{ Variables } & \multicolumn{3}{|c|}{ 2-h OGTT } & \multirow{2}{*}{ Total } & \multirow{2}{*}{$p$-value } \\
\hline & & Normal & IGT & DM & & \\
\hline \multirow[t]{3}{*}{$\mathrm{HbA1c}$} & Normal & $88(83.8 \%)$ & $14(66.7 \%)$ & $1(33.3 \%)$ & $103(79.8 \%)$ & $0.021 *$ \\
\hline & Prediabetes & $17(16.2 \%)$ & $6(28.6 \%)$ & $2(66.7 \%)$ & $25(19.4 \%)$ & \\
\hline & DM & 0 & $1(4.8 \%)$ & 0 & $1(0.8 \%)$ & \\
\hline Total & & $105(81.5 \%)$ & $21(16.1 \%)$ & $3(2.4 \%)$ & 129 & \\
\hline \multirow[t]{3}{*}{ FPG } & Normal & $81(77.1 \%)$ & $11(52.4 \%)$ & $1(33.3 \%)$ & $93(72.1 \%)$ & $<0.001 *$ \\
\hline & IFG & $24(22.9 \%)$ & $9(42.9 \%)$ & $1(33.3 \%)$ & $34(26.4 \%)$ & \\
\hline & DM & 0 & $1(4.8 \%)$ & $1(33.3 \%)$ & $2(1.6 \%)$ & \\
\hline Total & & $105(81.5 \%)$ & $21(16.1 \%)$ & $3(2.4 \%)$ & 129 & \\
\hline
\end{tabular}

$* p$-value $<0.05$ is significant, tested by Chi-square. 
Table 3. Clinical characters of lean and overweight/obese subjects diagnosed with PCOS.

\begin{tabular}{lccc} 
& \multicolumn{2}{c}{ Mean \pm SD } & \\
\cline { 2 - 3 } \multicolumn{1}{c}{ Variables } & $\begin{array}{c}\text { Lean PCOS } \\
(\mathbf{n = 3 0})\end{array}$ & $\begin{array}{c}\text { Overweight/Obese PCOS } \\
(\mathbf{n = 9 9 )}\end{array}$ & p- value \\
\hline Age $($ years $)$ & $22.73 \pm 5.00$ & $27.59 \pm 7.00$ & $0.001^{*}$ \\
BMI $\left(\mathrm{kg} / \mathrm{m}^{2}\right)$ & $21.78 \pm 2.30$ & $34.4 \pm 6.20$ & $<0.001^{*}$ \\
WC $(\mathrm{cm})$ & $79.60 \pm 5.57$ & $102.70 \pm 13.10$ & $<0.001^{*}$ \\
SBP $(\mathrm{mmHg})$ & $118.80 \pm 10.24$ & $125.00 \pm 14.00$ & $0.034^{*}$ \\
DBP $(\mathrm{mmHg})$ & $74.00 \pm 9.40$ & $75.48 \pm 11.10$ & 0.545 \\
Fasting insulin $(\mu \mathrm{U} / \mathrm{mL})$ & $15.24 \pm 20.77$ & $19.30 \pm 22.14$ & 0.394 \\
TT $(\mathrm{ng} / \mathrm{dL})$ & $28.63 \pm 22.99$ & $37.73 \pm 20.49$ & $0.041^{*}$ \\
FT $(\mathrm{ng} / \mathrm{dL})$ & $0.64 \pm 1.03$ & $0.78 \pm 0.50$ & 0.333 \\
SHBG $(\mathrm{nmol} / \mathrm{L})$ & $55.00 \pm 35.19$ & $36.15 \pm 32.21$ & $0.007^{*}$ \\
DHEA-S $(\mu \mathrm{g} / \mathrm{dL})$ & $199.00 \pm 101.9$ & $255.40 \pm 131.60$ & $0.034^{*}$ \\
\hline
\end{tabular}

${ }^{*} p$-value $<0.05$ is significant, tested by independent student t-test.

normal glucose state from those with abnormal glucose state (AUC: $0.645 ; 95 \%$ CI: 0.503-0.77; $p=0.03$ ).

\section{Discussion}

Women diagnosed with PCOS are more prone to have diabetes (5-10 times higher than the general population) especially in the presence of IR.(15) According to Androgen Excess Society (AES) guidelines, 2-h OGTT is recommended as a gold standard test to detect glycemic disorders in women diagnosed with PCOS especially those with at least one risk factor for diabetes.(2) In this study, an abnormal glucose metabolism was consistent with that reported in Europe (IGT $=12.4 \%, \mathrm{~T} 2 \mathrm{DM}=1.7 \%)$, but it was lower than that seen in American women with PCOS

Table 4. Pattern of glycemic disorders between lean and overweight/obese subjects with PCOS.

\begin{tabular}{|c|c|c|c|c|c|}
\hline \multicolumn{2}{|c|}{ Variables } & \multirow{2}{*}{$\begin{array}{c}\begin{array}{c}\text { Lean PCOS } \\
(\mathbf{n}=\mathbf{3 0})\end{array} \\
103.96 \pm 32.62\end{array}$} & \multirow{2}{*}{$\begin{array}{c}\begin{array}{c}\text { Overweight/Obese PCOS } \\
(\mathbf{n}=99)\end{array} \\
119.32 \pm 33.46\end{array}$} & \multirow{2}{*}{$\begin{array}{c}\begin{array}{c}\text { Total } \\
(\mathbf{n}=\mathbf{1 2 9})\end{array} \\
116.97 \pm 33.93\end{array}$} & \multirow{2}{*}{$\begin{array}{r}\boldsymbol{p} \text {-value } \\
0.033^{*}\end{array}$} \\
\hline 2-h OGTT (mg/dL) & Mean \pm SD & & & & \\
\hline & Normal, n (\%) & $27(90 \%)$ & $78(78.8 \%)$ & $105(81.5 \%)$ & $0.331 * *$ \\
\hline & IGT, n (\%) & $3(10 \%)$ & $18(18.2 \%)$ & $21(16.2 \%)$ & \\
\hline & DM, n (\%) & 0 & $3(3.0 \%)$ & $3(2.3 \%)$ & \\
\hline \multirow[t]{4}{*}{$\mathrm{FPG}(\mathrm{mg} / \mathrm{dL})$} & Mean \pm SD & $91.00 \pm 9.11$ & $95.00 \pm 11.22$ & $94.10 \pm 10.87$ & $0.081 *$ \\
\hline & Normal, n (\%) & $24(80 \%)$ & $69(69.7 \%)$ & $93(72.1 \%)$ & $0.462 * *$ \\
\hline & IFG, n $(\%)$ & $6(20 \%)$ & $28(28.3 \%)$ & $34(26.4 \%)$ & \\
\hline & DM, n (\%) & 0 & $2(2 \%)$ & $2(1.6 \%)$ & \\
\hline \multirow[t]{4}{*}{$\mathrm{HbA1c}(\%)$} & Mean \pm SD & $5.07 \pm 0.43$ & $5.26 \pm 0.51$ & $5.25 \pm 0.50$ & $0.92 *$ \\
\hline & Normal, n (\%) & $28(93.3 \%)$ & $75(75.8 \%)$ & $103(79.8 \%)$ & $0.108 * *$ \\
\hline & Prediabetes, n (\%) & $2(6.7 \%)$ & $23(23.2 \%)$ & $25(19.4 \%)$ & \\
\hline & DM, n (\%) & 0 & $1(1.0 \%)$ & $1(0.8 \%)$ & \\
\hline \multirow[t]{2}{*}{ HOMA-IR (\%) } & Mean \pm SD & $4.02 \pm 4.82$ & $4.51 \pm 5.91$ & $4.36 \pm 5.63$ & $0.685^{*}$ \\
\hline & IR, n (\%) & $14 / 30(46.7 \%)$ & 76/99 (76.8\%) & $90 / 129(69.8 \%)$ & $0.002 * *$ \\
\hline
\end{tabular}

$* p$-value $<0.05$ is significant, tested by independent student t-test. $* * p$-value $<0.05$ is significant, tested by Chi-square. 


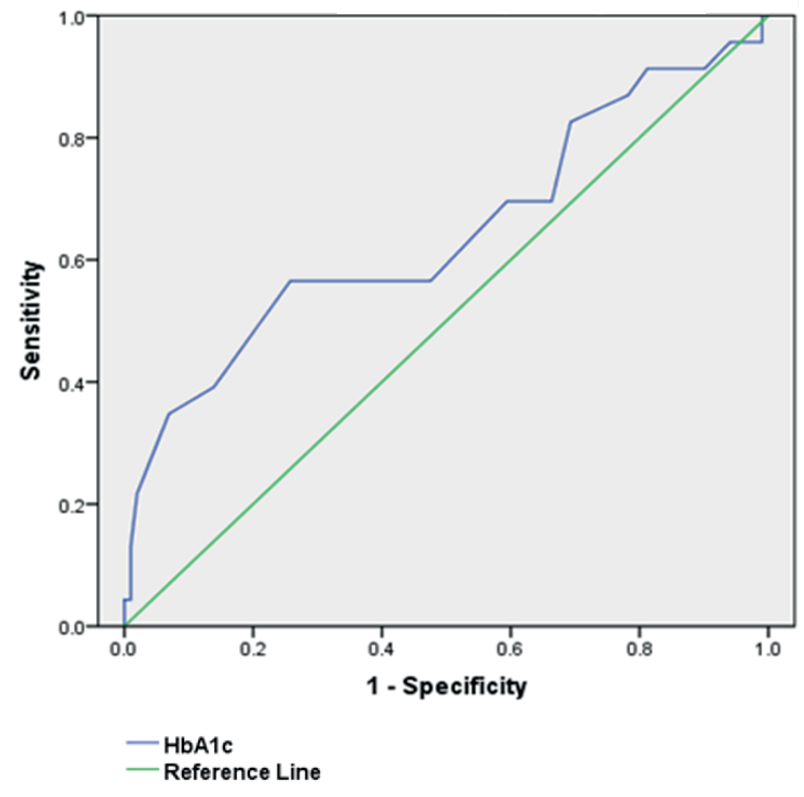

Figure 1. ROC curve for HbA1c in subjects diagnosed with PCOS. $p$-value $<0.05$ is assumed to be statistically significant.

(IGT=31-35\%，T2DM=7.5-10\%).(16,17) The difference between our results and American women could be related to genetic predisposition, personal behavior and ethnicity.

Prediabetes was diagnosed by either HbAlc or FPG in around one-fifth of women diagnosed with PCOS which was higher than that detected by 2-h OGTT, but more than half of prediabetes were having a normal glucose status by $2 \mathrm{~h}$ OGTT and around two-third of women with IGT were misinterpreted as normal glucose by HbAlc. The pattern of strikethrough diabetes and prediabetes diagnosis in this study by HbAlc might underestimate T2DM and overestimate prediabetes among women with PCOS, which was also observed in the National-Health and Nutrition-Examination Survey NHANES in 2010 for both women diagnosed with PCOS and non-PCOS populations (18), rendering HbAlc as unreliable screening test for dysglycemia in women with PCOS, especially during the detection of prediabetes and T2DM.

Still, HbA1c level has some benefits over 2-h OGTT like being a better estimate for chronic glycemic control by measuring plasma glucose over 2-3 months earlier, less day to day variability during periods of acute illnesses or stress, and has a greater convenience for example no need for fasting before the test.(4) In addition to that, some studies supported that $\mathrm{HbAlc}$ has a good correlation with complications of PCOS such as metabolic syndrome and cardiovascular events. $(19,20)$

In our study, FPG misinterpreted the diagnosis of glycemic disorder in one-fifth of women with hyperglycemia and more than half of women with IGT, and considered them as normal. These findings suggest that FPG could be a weak tool to screen for dysglycemia in women with PCOS which was also reported by an Austrian cohort study of 671 young and non-obese women with PCOS.(21) So that postprandial glucose rather than FPG could be more indicative of prediabetes risk in PCOS because of insulin secretory defect may be presented in PCOS as part of its pathophysiology.(22)

By using our cut-off value of $5.55 \%(37.2 \mathrm{mmol} / \mathrm{mol})$ for $\mathrm{HbA1c}$, around less than half of the women were below the cutoff value even though they were having an abnormal glucose state by the 2-h OGTT. The low sensitivity of $\mathrm{HbA} 1 \mathrm{c}$ in this study was also reported in a study done for screening women after delivery with previous gestational diabetes mellitus.(23) Moreover, the performance of HbA1c as a screening tool for dysglycemia in women with PCOS, had also some potential weakness in a study on a Turkish woman with PCOS.(24) This low sensitivity of HbAlc could be explained by two factors; firstly, in early state of dysglycemia, HbA1c has a slow reactions to B-cell chains of hemoglobin during the lifespan of red blood cells, so that it is mainly applied to assess chronic glycemic state rather than recent dysglycemia. Secondly, many women modify their lifestyles as soon as the diagnosis of PCOS was established which might lead to a decline in $\mathrm{HbAlc}$ rather than in 2-h OGTT. Thus, the 2-h OGTT seems to be the most reasonable test to detect glycemic disorders among women diagnosed with PCOS.

Obesity was predominant in women diagnosed with PCOS in this study, more than three-quarters of enrolled women were either overweight or obese, and most of them has IR, which was similar to that reported in a cohort study from Alabama.(25) Those overweight/obese PCOS were significantly having a higher mean 2-h OGTT and more glycemic disorders (IGT $=18.2 \%, \mathrm{~T} 2 \mathrm{DM}=3 \%$ ) diagnosed by 2-h OGTT than lean PCOS. This high rate of obesity and IR in relatively young women could be attributed, in part to a modern lifestyle with sedentary habit and consuming a carbohydrate rich diet that is furthermore leading to increase in prevalence of PCOS and diabetes throughout the world $(25,26)$.

Surprisingly, prediabetes was diagnosed in nearly $10 \%$ of lean PCOS by 2-h OGTT. This finding was seen before and explained by intra-abdominal fat rather than BMI correlation with IR and subsequent dysglycemia.(27) A finding criticizes the ADA and AES recommendations to screen for T2DM in asymptomatic women with PCOS if their BMI equal or more than $25 \mathrm{~kg} / \mathrm{m}^{2}$.(2). In this study, 
IR was observed in both overweight/obese and lean PCOS, though it was significantly more obvious in overweight/ obese women. This makes the association between PCOS and IR more clear and IR could be an independent factor in the pathophysiology of PCOS regardless of obesity. (28) As obesity and IR affect SHBG synthesis in the liver, overweight/obese women were significantly having a higher TT than lean women, but FT was nearly consistent in both groups. This is explained by excess insulin increase free androgen through either stimulating androgen secretion from the theca cells or inhibiting SHBG production from the liver.(29,30)

There are some limitations of this study including, firstly a lack of weight-matched control group to compare screening for dysglycemia using HbAlc, secondly the distribution of glycemic disorders and IR among the phenotype of PCOS was not studied, and finally this is a single tertiary center study which make the generalization of the study findings difficult.

\section{Conclusion}

Screening of glycemic disorders is crucial for PCOS by using 2-h OGTT regardless risk factor and HbA1c seems to be an unsatisfactory screening tool to predict glycemic disorders in PCOS women.

\section{Acknowledgements}

We would like to express greatest thanks to participants for their cooperation and a sincere gratitude to all our colleagues and paramedics especially laboratory personals who are working in Faiha specialized diabetes, endocrine and metabolism center (FDEMC) for their continuous supportive efforts in facilitating highly scientific research environment.

\section{Authors Contribution}

MTA contributed to the study design and execution, data analysis, manuscript drafting and critical discussion. AKM contributed to the study execution, data analysis, and manuscript drafting. AAM contributed to the study design and execution, data analysis, manuscript drafting and critical discussion. All authors were involved in the preparation of the manuscript and approved the final manuscript.

\section{References}

1. Goodman NF, Cobin RH, Futterweit W, Glueck JS, Legro RS, Carmina E, et al. American association of clinical endocrinologists, american college of endocrinology, and androgen excess and pcos society disease state clinical review: Guide to the best practices in the evaluation and treatment of polycystic ovary syndrome--part 1. Endocr Pract. 2015; 21: 1291-300.

2. Goodman NF, Cobin RH, Futterweit W, Glueck JS, Legro RS, Carmina E, et al. American association of clinical endocrinologists, american college of endocrinology, and androgen excess and pcos society disease state clinical review: guide to the best practices in the evaluation and treatment of polycystic ovary syndrome--part 2. Endocr Pract. 2015; 21: 1415-26.

3. DeUgarte CM, Bartolucci AA, Azziz R. Prevalence of insulin resistance in the polycystic ovary syndrome using the homeostasis model assessment. J Fertility Sterility Diabetes. 2005; 83: 1454-60.

4. American Diabetes A. 2. Classification and Diagnosis of Diabetes: Standards of Medical Care in Diabetes-2020. Diabetes Care. 2020; 43 (Suppl 1): S14-31.

5. Rotterdam EA-SPCWG. Revised 2003 consensus on diagnostic criteria and long-term health risks related to polycystic ovary syndrome. Fertil Steril. 2004; 81: 19-25.

6. Pall M, Azziz R, Beires J, Pignatelli D. The phenotype of hirsute women: a comparison of polycystic ovary syndrome and 21-hydroxylase-deficient nonclassic adrenal hyperplasia. Fertil Steril. 2010; 94: 684-9.

7. Mansour AA, Al-Hassan AA, Al-Jazairi MI. Cut-off values for waist circumference in rural Iraqi adults for the diagnosis of metabolic syndrome. Rural Remote Health. 2007; 7(4): 765.

8. Alberti KGMM, Zimmet P, Shaw J. The IDF consensus worldwide definition of the metabolic syndrome. Diabet Med. 2006; 23: 46980.

9. Martin KA, Anderson RR, Chang RJ, Ehrmann DA, Lobo RA, Murad $\mathrm{MH}$, et al. Evaluation and treatment of hirsutism in premenopausal women: an endocrine society clinical practice guideline. J Clin Endocrinol Metab. 2018; 103: 1233-57.

10. Braunstein GD, Reitz RE, Buch A, Schnell D, Caulfield MP Testosterone reference ranges in normally cycling healthy premenopausal women. J Sex Med. 2011; 8: 2924-34.

11. Balen AH, Laven JS, Tan SL, Dewailly D. Ultrasound assessment of the polycystic ovary: international consensus definitions. Hum Reprod Update. 2003; 9: 505-14.

12. Nordenstrom A, Falhammar H. Management of endocrine disease: Diagnosis and management of the patient with non-classic $\mathrm{CAH}$ due to 21-hydroxylase deficiency. Eur J Endocrinol. 2019; 180: R127-R45.

13. Vermeulen A, Verdonck L, Kaufman JM. A critical evaluation of simple methods for the estimation of free testosterone in serum. J Clin Endocrinol Metab. 1999; 84: 3666-72.

14. Gayoso-Diz P, Otero-González A, Rodriguez-Alvarez MX, Gude F, García F, De Francisco A, et al. Insulin resistance (HOMAIR) cut-off values and the metabolic syndrome in a general adult population: effect of gender and age: EPIRCE cross-sectional study. BMC Endocr Disord. 2013; 13: 47. doi: 10.1186/1472-6823-13-47.

15. Diamanti-Kandarakis E, Dunaif A. Insulin resistance and the polycystic ovary syndrome revisited: an update on mechanisms and implications. Endocr Rev. 2012; 33: 981-1030.

16. Ehrmann DA BR, Rosenfield RL, Cavaghan MK, Imperial J. Prevalence of impaired glucose tolerance and diabetes in women with polycystic ovary syndrome. Diabetes Care. 1999; 22: 141-6. 
17. Trakakis E, Basios G, Peppa M, Simeonidis G, Labos G, Creatsa M, et al. The prevalence of glucose metabolism abnormalities in Greek women with polycystic ovary syndrome. Gynecol Endocrinol. 2012; 28: 867-70.

18. Cowie CC, Rust KF, Byrd-Holt DD, Gregg EW, Ford ES, Geiss LS, et al. Prevalence of diabetes and high risk for diabetes using A1C criteria in the U.S. population in 1988-2006. Diabetes Care. 2010; 33: $562-8$

19. de Medeiros SF, Yamamoto MM, Bueno HB, Belizario D, Barbosa JS. Prevalence of elevated glycated hemoglobin concentrations in the polycystic ovary syndrome: anthropometrical and metabolic relationship in amazonian women. J Clin Med Res. 2014; 6: 278-86.

20. Mortada R, Comerford K, Kallail KJ, Karakas SE. Utility of hemoglobin-A1C in nondiabetic women with polycystic ovary syndrome. Endocr Pract. 2013; 19: 284-9.

21. Lerchbaum E, Schwetz V, Giuliani A, Obermayer-Pietsch B. Assessment of glucose metabolism in polycystic ovary syndrome: $\mathrm{HbA} 1 \mathrm{c}$ or fasting glucose compared with the oral glucose tolerance test as a screening method. Human reproduction (Oxford, England). 2013; 28: 2537-44.

22. Holte J, Bergh T, Berne C, Berglund L, Lithell H. Enhanced early insulin response to glucose in relation to insulin resistance in women with polycystic ovary syndrome and normal glucose tolerance. J Clin Endocrinol Metab. 1994; 78: 1052-8.

23. Picon MJ, Murri M, Munoz A, Fernandez-Garcia JC, Gomez-Huelgas R, Tinahones FJ. Hemoglobin A1c versus oral glucose tolerance test in postpartum diabetes screening. Diabetes Care. 2012; 35: 164853.

24. Celik C, Abali R, Bastu E, Tasdemir N, Tasdemir UG, Gul A.
Assessment of impaired glucose tolerance prevalence with hemoglobin A(1)c and oral glucose tolerance test in 252 Turkish women with polycystic ovary syndrome: a prospective, controlled study. Hum Reprod. 2013; 28: 1062-8.

25. Yildiz BO, Knochenhauer ES, Azziz R. Impact of obesity on the risk for polycystic ovary syndrome. J Clin Endocrinol Metab. 2008; 93: 162-8.

26. Rahman MN, Diantini A, Fattah M, Barliana MI. Nutritional biomarkers for predicting pancreatic beta cell failure in central obesity. Indones Biomed J. 2021: 12: 19-26.

27. Wehr E, Gruber HJ, Giuliani A, Moller R, Pieber TR, ObermayerPietsch B. The lipid accumulation product is associated with impaired glucose tolerance in PCOS women. J Clin Endocrinol Metab. 2011; 96: E986-90.

28. Legro RS, Kunselman AR, Dodson WC, Dunaif A. Prevalence and predictors of risk for type 2 diabetes mellitus and impaired glucose tolerance in polycystic ovary syndrome: a Prospective, controlled study in 254 affected women. J Clin Endocrinol Metab. 1999; 84: 165-9.

29. Nestler JE, Jakubowicz DJ, de Vargas AF, Brik C, Quintero N, Medina F. Insulin stimulates testosterone biosynthesis by human thecal cells from women with polycystic ovary syndrome by activating its own receptor and using inositolglycan mediators as the signal transduction system. J Clin Endocrinol Metab. 1998; 83: 2001-5.

30. Nestler JE, Powers LP, Matt DW, Steingold KA, Plymate SR, Rittmaster RS, et al. A direct effect of hyperinsulinemia on serum sex hormone-binding globulin levels in obese women with the polycystic ovary syndrome. J Clin Endocrinol Metab. 1991; 72: 83-9. 